\title{
TOLERÂNCIA CRUZADA INDUZIDA POR CHOQUE TÉRMICO NA GERMINAÇÃO DE SEMENTE DE FEIJÃ̃ ${ }^{1}$
}

\author{
CECI CASTILHO CUSTÓDIO5 ${ }^{5}$ MÁRCIA REGINA VIVAN², RITA DE CÁSSIA ALVES NUNES³, \\ EDNA ANTÔNIA TORQUATO DE AGOSTINI ${ }^{2,4}$
}

\begin{abstract}
RESUMO - Estresse pode ser definido como um fator externo, que exerce influência desvantajosa sobre a planta. Em regiões tropicais, as culturas agrícolas sofrem estresse abiótico principalmente por períodos de deficiência de água e altas temperaturas. A tolerância cruzada permite as plantas se aclimatarem a uma gama de diferentes estresses após exposição a um estresse específico. O objetivo neste trabalho foi avaliar a tolerância ao estresse hídrico durante a germinação das sementes de feijão sob influência da tolerância cruzada induzida por choque térmico. As sementes de feijão cultivar 'IAPAR 81 ' foram submetidas ao processo de embebição, em substrato papel umedecido com água pura sob temperatura de $20^{\circ} \mathrm{C}$ por 24 horas. A seguir, parte foi mantida nessa temperatura e parte transferida para o choque frio por 24 horas a $7^{\circ} \mathrm{C}$ no ensaio 1 e $13^{\circ} \mathrm{C}$ no ensaio 2 e outra parte para o choque quente por 24 horas a $38 \mathrm{oC}$ no ensaio 1 e $33 \mathrm{oC}$ no ensaio 2 , sem troca do substrato. Tanto as sementes que passaram pelo choque como as que não passaram (controle) foram transferidas para substrato papel simulando diferentes potenciais hídricos, $0 ;-0,6 ;-0,9$ e -1,2MPa, no ensaio 1 e $0 ;-0,3$; -0,6; -0,9 e 1,2MPa no ensaio 2, induzidos por manitol nas seguintes concentrações: $0 ; 22,29 ; 44,58$; 66,87 e 89,17 g.L $L^{-1}$. Os tratamentos foram avaliados através da porcentagem de germinação, plântulas anormais, sementes mortas e avaliações do desenvolvimento (massa seca da parte aérea, massa seca de raiz, massa seca total e relação raiz/parte aérea). O melhor desempenho das sementes que passaram por choque, de $7 \mathrm{oC}$ por $24 \mathrm{~h}$ ou de $33 \mathrm{oC}$ por $24 \mathrm{~h}$, à restrição hídrica no início do desenvolvimento, permite afirmar que ocorre indução de tolerância cruzada e que esta pode ser induzida no início do processo de embebição em sementes de feijão.
\end{abstract}

Termos para indexação: choque frio, choque quente, deficiência hídrica, Phaseolus vulgaris L.

\section{CROSS TOLERANCE INDUDED BY TERMIC SHOCK IN THE BEAN SEED GERMINATION}

\begin{abstract}
Stress could be defined as an external factor that may have some disadvantageous influence on the plant. In tropical regions, crops suffer abiotic stress especially due to water deficit and high temperature. Cross tolerance allows the plants to be acclimated after a short exposure to a specific stress. The objective of this study was water stress tolerance during bean seed germination influenced by heat shock induced cross tolerance. Seed of the common bean cv 'IAPAR 81 ' were submitted to imbibition in substrate paper with pure water at $20^{\circ} \mathrm{C}$ for $24 \mathrm{~h}$. One third of the seeds
\end{abstract}

${ }^{1}$ Submetido em 08/08/2007. Aceito para publicação em 13/01/2009. Parte da Dissertação de Mestrado do primeiro autor apresentada a UNOESTE.

${ }^{2}$ Eng. Agr., pós graduando do Programa de Pós-Graduação em Agronomia da UNOESTE, e-mail:mvivan@hotmail.com

${ }^{3}$ Biologo (a), pós graduando do Programa de Pós-Graduação em Agronomia

\section{da UNOESTE}

${ }^{4}$ Biologo (a), técnica do Laboratório de Sementes da UNOESTE

${ }^{5}$ Eng. Agr., Dr., Prof. Departamento de Biologia Vegetal e Fitossanidade da UNOESTE, Presidente Prudente, SP, CEP 19067175. e-mail: ceci@ unoeste.br 
were maintained at that temperature. One third were submitted to cold shock for $24 \mathrm{~h}$ at $7^{\circ} \mathrm{C}$ in the first assay and $13^{\circ} \mathrm{C}$ in the second and the final part were submitted to heat shock for $24 \mathrm{~h}$ at $38^{\circ} \mathrm{C}$ and $33^{\circ} \mathrm{C}$ as used for the cold shocks; in all experiments there was no change of substrate. Seeds submitted or not to shock were transferred to paper substrate simulating water potential of $0 ;-0.6$; -0.9 and $-1.2 \mathrm{MPa}$, in the first experiment and $0 ;-0.3 ;-0.6 ;-0.9$ and $-1.2 \mathrm{MPa}$ in the second experiment using mannitol at: $0 ; 22.29 ; 44.58 ; 66.87$ and 89.17 g.L.- ${ }^{-1}$ Treatments were evaluated by germination percentage, abnormal plants, dead seeds and seedling evaluation (shoot, root and total dry matter and by relation of root/shoot). The best development, in water restriction in early germination, was of that seeds that passed through $7^{\circ} \mathrm{C}$ or $33^{\circ} \mathrm{C}$ for $24 \mathrm{~h}$, that allowed the affirmation that induced cross tolerance occurred and that it could be induced at the beginning of the imbibition in bean seeds.

Index terms: cold shock, heat shock, water deficit, Phaseolus vulgaris L.

\section{INTRODUÇÃO}

Estresse pode ser definido como um fator externo, que exerce influência desvantajosa sobre a planta (Taiz e Zeiger, 2004). Estresse osmótico e temperatura afetam a produtividade das culturas e limitam a expansão da agricultura em muitas regiões do mundo (Song et al., 2005). O modo como as plantas respondem ao estresse é crucial para a produtividade. Pela perspectiva agrícola, ambiente desfavorável constitui o fator mais significativo conduzindo a substancial e incalculável diminuição na produtividade. As plantas desenvolveram estratégias únicas para responder a cada mudança ambiental, exaustivamente monitorando o ambiente que as rodeiam e ajustando seus sistemas metabólicos para manter a homeostase. A severidade do estresse, a genética e a história individual determina a cada dia sobrevivência ou morte (Pastori e Foyer, 2002).

Tolerância ao estresse é a aptie\& Zeiger, 2004). As plantas se aclimatam ao estresse biótico e abiótico por dispararem uma cascata ou rede de eventos que inicia com a percepção do estresse e termina com a expressão de um conjunto de genes alvo fazendo uso de rotas e componentes comuns em resposta ao estresse. Este fenômeno, que é conhecido como tolerância cruzada, permite às plantas se aclimatarem a uma gama de diferentes estresses após exposição a um estresse específico (Pastori e\& Foyer, 2002). Este fenômeno pode ser explicado por alto grau de sobreposição entre conjuntos de genes determinantes da tolerância a um estresse particular (Rizhsky et al., 2002; Foolad et al., 2003) ou devido aos mecanismos de sinalização e resposta ao estresse envolverem rotas metabólicas comuns (Borisova et al., 2001). Adaptação, no entanto, em geral se refere a um nível de resistência adquirido por processo de seleção durante muitas gerações (Taiz e Zeiger, 2004). A Adaptação de uma espécie a um ambiente desfavorável é um forte requisito para sua sobrevivência (Gimalov et al., 1996).

A interação genótipo-ambiente é a chave determinante para a composição dos tecidos (fatores de qualidade), anatomia, morfologia e desenvolvimento. As plantas têm que integrar uma diversidade de sinais ambientais e metabólicos que junto regulam a expressão gênica durante o estresse. Não é estranho que um sistema comum de sinais tem promovido defesas e proteção contra os desafios de um ambiente danoso (Pastori e Foyer, 2002).

Exemplo de tolerância cruzada envolve deficiência hídrica e excesso de calor ou vice-versa (Rizhsky et al., 2002), excesso de calor e salinidade (Song et al., 2005), excesso de calor e estresse de frio (Takahashi et al., 1994), radiação UV-B e deficiência de água (Borisava et al., 2001). A deficiência hídrica, por exemplo, muitas vezes está associada à salinidade na biosfera das raízes e ao estresse por calor nas folhas (resultante de diminuição do esfriamento evaporativo devido à baixa transpiração), enquanto o resfriamento e o congelamento levam a reduções na atividade hídrica e estresse osmótico (Taiz e Zeiger, 2004).

Embora haja muitas informações sobre tolerância em plântulas ou em estágios posteriores, há pouca informação na relação de tolerância cruzada em sementes germinando e em plântulas muito jovens (Song et al., 2005).

O conceito de temperaturas cardeais - temperatura 
mínima, máxima e ótima - foi proposto por Sachs no século passado e, desde então, essa abordagem das relações planta/ temperatura tem norteado inúmeros trabalhos envolvendo o desenvolvimento vegetal, em particular na área da germinação de sementes. Assim, observa-se que a germinabilidade é máxima dentro de faixa variável de temperatura, acima e abaixo da qual a germinação final tende a diminuir. Esse padrão de resposta também é aplicável ao parâmetro velocidade de germinação (Marcos Filho, 2005).

Tanto culturas de origem temperada e tropical sofrem injúrias quando expostas a baixas temperaturas. Injúria por frio é uma desordem fisiológica que se desenvolve em algumas plantas tropicais e subtropicais quando expostas à temperatura abaixo de 10 a $12{ }^{\circ} \mathrm{C}$, mas não congelantes (Sabehat et al., 1996). Como sintomas de injúria por temperatura podem ser citados germinação e crescimento reduzido e diminuição da viabilidade (Zaiter et al., 1994; Rab e Salveit, 1996).

Para verificar o efeito de altas ou baixas temperaturas, constantes ou em ciclos alternados, 10 genótipos de feijoeiro foram germinados e a determinação de prolina foi utilizada como indicador de estresse. Machado Neto et al. (2004) concluíram que prolina pode ser usada como indicativo de estresse por temperatura nas linhagens responsivas, $24 \mathrm{~h}$ após a exposição. As temperaturas de choque utilizadas foram 8 e $37^{\circ} \mathrm{C}$.

Em feijoeiro também tem sido observada uma relação entre taxa de germinação e taxa de crescimento, ou seja, plantas que apresentam germinação lenta, muito provavelmente apresentarão crescimento lento. Em face dessa característica da tribo Phaseoleae, em particular do gênero Phaseolus, diversos estudos (Braak e Koistra, 1975; Hardwick e Andrews, 1980; Zaiter et al., 1994) tem sido realizados no sentido de se desenvolverem linhagens tolerantes a baixas temperaturas - para regiões de clima frio - ou para temperaturas consideradas supra ótimas para regiões sujeitas à temperaturas elevadas. Essa última condição é particularmente marcante em regiões tropicais, que incluem a maior proporção do território brasileiro, e onde não é rara a temperatura ao nível do solo exposto atingir valores da ordem de $45-50^{\circ} \mathrm{C}$. Em experimento realizado em um solo argissolo vermelho amarelo distrófico arênico, a temperatura do solo foi determinada durante todo o ciclo do feijoeiro, realizando-se leitura a cada $10 \mathrm{~min}$, em um sistema automatizado instalados na frofundidade de 0,025 a $0,1 \mathrm{~m}$. Na menor profundidade o plantio direto seguido de uma aração e uma gradagem apresentou temperatura máxima de $42,2^{\circ} \mathrm{C}$, o plandio direto removido por escaficador de $43,7^{\circ} \mathrm{C}$ e o plantio direto de $36,1^{\circ} \mathrm{C}$ (Silva et al., 2006). Em feijão, a faixa de temperatura ótima estaria entre 18 e $31^{\circ} \mathrm{C}$, enquanto que a faixa de temperatura máxima entre 35 e $39^{\circ} \mathrm{C}$ e mínimas entre 8 a $13^{\circ} \mathrm{C}$; temperaturas acima de $40^{\circ} \mathrm{C}$ fortemente inibiram a germinação (Machado Neto et al., 2006b).

De maneira similar aos processos desencadeados por estresse com temperaturas altas, as baixas também podem produzir alterações no metabolismo protéico. Todavia, as respostas a choques frios são diferentes das respostas a altas temperaturas (Gimalov et al., 1996). Em cultivares/linhagens de feijoeiro tolerantes ao frio, observou-se um aumento na síntese de certas proteínas em plântulas submetidas a baixas temperaturas (Zaiter et al., 1994).

A disponibilidade deágua e a maneira como elaéabsorvida pelas sementes afeta a germinação, o desenvolvimento inicial das raízes e a elongação da parte aérea (Braccini et al., 1996; Machado Neto et al., 2004; Costa et al., 2004; Machado Neto et al., 2006a). Estes fatores são altamente influenciados pelo potencial matricial, pela textura do solo e área de contato solo/ raiz. Potenciais muito negativos do substrato, especialmente no início da germinação, podem diminuir a absorção de água tornando a germinação impossível (Braccini et al., 1996).

Trabalhos com sementes de diversas espécies têm sido conduzidos sob condições de deficiência hídrica, com o objetivo de se determinar o vigor em condições de estresse hídrico. Para tanto, são usadas diversas soluções osmóticas para simular um ambiente com pouca umidade. Dentre estas pode-se citar: PEG (polietileno glicol); Manitol; $\mathrm{CaCl}_{2}$ (cloreto de cálcio); $\mathrm{KCl}$ (cloreto de potássio) e $\mathrm{NaCl}$ (cloreto de sódio). Quantidades específicas, para cada um destes osmóticos, simulam um determinado potencial osmótico e estes potenciais podem ser estabelecidos pela equação de Van't Hoff (Braga et al., 1999; Souza e Cardoso, 2000).

Estudos usando osmóticos para simulação de deficiência de água no início da germinação mostram que sementes de soja de diferentes tamanhos foram pouco afetadas até o potencial de -1,2MPa (Costa et al., 2004). Sementes de feijão germinadas em diferentes potenciais hídricos obtidos a partir de soluções osmóticas de manitol, $\mathrm{CaCl}_{2}, \mathrm{KCl}$ e $\mathrm{NaCl}$ mostraram que as soluções de manitol e $\mathrm{CaCl}_{2}$ não apresentaram diferenças estatísticas na maioria dos resultados analisados até a concentração de $-0,6 \mathrm{MPa}$, enquanto as soluções de $\mathrm{KCl}$ e $\mathrm{NaCl}$, além de funcionaram como reguladores osmóticos, manifestaram toxidez às sementes de feijão, não sendo recomendadas, portanto, como simuladores de deficiência hídrica (Machado Neto et al., 2006a).

Em condições de plena disponibilidade de água no solo, as sementes, principalmente as mais secas, podem absorver água rapidamente, ocasionando rupturas em seus tecidos, 
com conseqüentes prejuízos à germinação (Braga et al., 1999) sendo que a planta de feijão (Phaseolus vulgaris L.) possui grande sensibilidade à falta de água após a semeadura; valores superiores a 3,5 atm(-0,35MPa), no solo, podem reduzir drasticamente a germinação e a elongação de células (Durval \& Fancelli, 2000), contudo mesmo após 6 dias em condições de deficiência a -1,2MPa havia germinação, em laboratório, em cultivares de feijoeiro (Machado Neto et al., 2006a).

Sementes de feijão, com diferentes potenciais fisiológicos, expostos ao estresse hídrico induzido por manitol, apresentaram redução na germinação, primeira contagem, velocidade de germinação, comprimento e peso seco de parte aérea e de raízes, bem como um aumento do número de plântulas anormais em potenciais de $-0,4$ a $-0,6 \mathrm{MPa}$ (Braga et al., 1999); em soja, efeito semelhante ocorreu em plantas submetidas ao estresse hídrico por cloreto de sódio (Santos et al., 1996).

Marur et al. (1994) argumentam que tecidos vegetais mostram diversas alterações das vias metabólicas em resposta ao déficit hídrico, podendo estas ocorrer em um destes três níveis: i) perturbações das vias metabólicas levando a um acúmulo ou perdas de metabólicos; ii) alterações das atividades enzimáticas; iii) alterações dos padrões protéicos.

Proteínas desempenham um papel fundamental na modulação da resposta da planta ao estresse. Ferguson et al.(1990) citam que temperaturas elevadas podem direta ou indiretamente injuriar proteínas vegetais, pela inativação de enzimas, por alterações na conformação de peptídeos ou por desestruturação de complexos em membrana. Uma das funções das proteínas de choque térmico está relacionada à prevenção da desnaturação de proteínas durante a desidratação celular (Nepomuceno et al., 2002). Dentro desse campo, importantes avanços tem sido realizados no entendimento das respostas moleculares a temperaturas altas ou choque de calor (Vierling,1991). Araújo et al. (2003) atestam que plantas de oito cultivares de feijão submetidas, após o período de crescimento, ao choque de duas horas a $40^{\circ} \mathrm{C}$, exibiram habilidade de expressão de proteínas de choque térmico de pequeno peso molecular. Por outro lado, sementes secas não apresentaram uma banda específica da fração das proteínas resistentes ao calor em um estudo no qual as sementes eram submetidas a altas temperaturas de secagem (Jose et al., 2005).

Alguns estudos atestam que é possível atenuar o estresse hídrico através da indução das proteínas de choque térmico ou através de utilização de substâncias osmoprotetoras, como indução de dissacarídeos osmoprotetores, poliaminas ou indução de enzimas extratoras de radicais livres (Maity et al., 2000; McCue et al., 2000; Matovina \& Blake, 2001; Sung Shim et al., 2003; Panda e Khan, 2004; Wahid \& Shabbir, 2005; Neid \& Biesboer et al., 2005; Kumari et al., 2006). Nesse sentido, a atenuação do estresse hídrico foi obtida em sementes submetidas às soluções acrescidas de poliaminas, devido ao significativo aumento na porcentagem de germinação (Fonseca e Perez, 2003).

Por outro lado, a tolerância cruzada pode ser um importante mecanismo de atenuação do estresse. Marin et al. (2004) relatam que o efeito do alumínio associado ao estresse hídrico na germinação de sementes de guandu foi evidenciado até $-0,9 \mathrm{MPa}$, onde as menores concentrações de alumínio ( 0 a $5 \mathrm{mmol} . \mathrm{dm}^{-3}$ ) estimularam o desenvolvimento das plântulas em condições de estresse hídrico até -0,6MPa. Em trigo, sementes pré-tratadas a $33^{\circ} \mathrm{C}$ ou em solução - $0,8 \mathrm{MPa}$ de NACl por diversos períodos aumentaram tolerância ao subseqüente estresse hídrico ou de calor, mensurado por porcentagem de germinação e massa seca de plântulas 5 dias após o início do experimento (Song et al., 2005).

Cayuela et al. (2001) estudaram pré-tratamento de plântulas com solução de $\mathrm{NaCl}$ para aumentar a produtividade de plantas de tomate irrigadas com água salina. Os resultados mostraram aclimatação de plantas de tomate ao crescimento em condições salinas após 15 dias de pré-tratamento com baixa concentração de $\mathrm{NaCl}$ (metade) que aquela usada durante o crescimento. Após 20 dias de tratamento $(100 \mathrm{mM}$ $\mathrm{NaCl}$ ), a biomassa de plantas aclimatadas aumentou significativamente em comparação àquelas não tratadas quando o pré-tratamento foi aplicado à plântulas de 5 folhas, mas não no estágio de 2 folhas. Estes resultados indicaram que mudanças, em crescimento e fisiologia, induzidas por pré-tratamento no estágio de plântula, são mantidos pelo ciclo de vida da planta.

Assim, espera-se que o emprego de temperaturas altas ou baixas, durante uma fase em que a semente possa responder ao estímulo ou seja, durante a embebição, possa induzir a expressão de genes, possibilitando às plântulas em crescimento desenvolverem habilidade de tolerância aos outros fatores ambientais, como por exemplo deficiência hídrica, configurando-se uma tolerância cruzada, abrindo a possibilidade de aplicação da técnica como tratamento de sementes por empresas produtoras.

O objetivo deste trabalho foi de verificar se choque térmico aplicado durante a embebição pode levar a aquisição de tolerância à deficiência hídrica, ou seja, se ocorre indução de tolerância cruzada durante o início do processo de germinação. 


\section{MATERIAL E MÉTODOS}

Os ensaios foram conduzidos no Laboratório de Análise de Sementes da Universidade do Oeste Paulista (UNOESTE), localizada em Presidente Prudente - SP. Foram utilizadas sementes de feijão do cultivar IAPAR 81, obtidas junto ao Instituto Agronômico do Paraná, em dois ensaios 1 e 2, conduzidos respectivamente nos meses de outubro de 2005 e fevereiro de 2006. As sementes foram submetidas ao processo de embebição, em substrato papel umedecido com água pura, na proporção 2,25 vezes o peso do substrato seco, sob temperatura de $20^{\circ} \mathrm{C}$ por 24 horas. A seguir, parte foi mantida nessa temperatura e parte transferida para o choque frio por 24 horas a $7^{\circ} \mathrm{C}$ no ensaio 1 e $13^{\circ} \mathrm{C}$ no ensaio 2 , obtidas em câmara climática, e outra parte para o choque quente por 24 horas a $38^{\circ} \mathrm{C}$ no ensaio 1 e $33^{\circ} \mathrm{C}$ no ensaio 2 , obtidas em equipamento tipo banho Maria, sem troca do substrato. Tanto as sementes que passaram pelo choque, como as que não passaram (controle), foram transferidas para substrato papel simulando diferentes potenciais hídricos, $0 ;-0,6 ;-0,9$ e $-1,2 \mathrm{MPa}$, no ensaio 1 e $0 ;-0,3 ;-0,6 ;-0,9$ e 1,2MPa no ensaio 2, induzidos por manitol nas seguintes concentrações: 0 ; 22,29; 44,58; 66,87 e 89,17 g.L.-1 , usando a fórmula de Van't Hoff (Braga et al., 1999).

Cada parcela foi composta por amostras de 50 sementes dispostas em três folhas de papel toalha, duas como base e uma como cobertura, enroladas e colocadas em sacos plásticos de polietileno. Foi realizada uma única contagem aos sete dias após semeadura onde se computaram plântulas normais, anormais e sementes mortas (Brasil, 1992). Os resultados foram expressos em porcentagem. Para avaliação do desempenho das plântulas, utilizaram-se as plântulas normais obtidas no teste de germinação que, depois de seccionadas em parte aérea e raiz, foram colocadas em sacos de papel e secas em estufa a $60^{\circ} \mathrm{C}$ por 48 horas. O material seco, após um período para esfriar em dessecador, foi pesado em balança analítica com precisão de 0,001g (Nakagawa, 1999).

O delineamento experimental utilizado em cada experimento foi inteiramente casualizado com tratamentos em arranjo fatorial de 2 condições (sementes submetidas e não submetidas ao choque térmico) e 5 níveis de potencial hídrico do substrato com quatro repetições por tratamento. Os dados porcentuais foram normalizados pela transformação de arcsen da raiz quadrada de x.100-1. Aplicou-se teste F para análise da variância e quando esta foi significativa utilizouse regressão polinomial para análise dos níveis de potencial e determinação de equações significativas com menor grau do polinômio e com maior coeficiente de determinação
$\left(\mathrm{R}^{2}\right)$. Dentro de cada nível de potencial, as médias foram comparadas através do teste Tukey com 5\% de significância. Para análise utilizou-se o programa estatístico SANEST (Zonta et al., 1984).

\section{RESULTADOS E DISCUSSÃO}

Com o aumento da restrição de água ocorreu diminuição da germinação (Figura 1A) em, aproximadamente, 20\%, e aumento de plântulas anormais para as sementes que não passaram pelo choque frio de $7^{\circ} \mathrm{C}$ enquanto as sementes que passaram pelo choque não apresentaram perda de germinação com o aumento da restrição hídrica (Figura1 A e C). A porcentagem de sementes mortas não mudou em função dos níveis de potencial hídrico (Figura 1E). Respostas promissoras foram obtidas para os parâmetros relacionados com o desenvolvimento das plântulas. Os resultados mais expressivos ocorreram no potencial de $-1,2 \mathrm{MPa}$, que proporcionou acentuada restrição hídrica. Neste potencial, as plântulas oriundas das sementes que receberam o choque frio desenvolveram maior massa seca de parte aérea (Figura 2A), massa seca de raiz (Figura 2C) e massa seca total de plântula (Figura 2E). A relação raiz/parte aérea não respondeu aos níveis de potencial e ao tratamento de choque (Figura $2 \mathrm{G}$ ).

No ensaio 2 utilizou-se a temperatura de $13^{\circ} \mathrm{C}$ para produzir o choque frio. As sementes que passaram pelo choque germinaram mais que aquelas que não passaram até o potencial de -0,9MPa (Figura 1B). As sementes que passaram pelo choque também apresentaram menor número de plântulas anormais no intervalo entre zero e $-0,9 \mathrm{MPa}$ (Figura 2D). O número de sementes mortas manteve-se constante em função da diminuição do potencial hídrico do substrato para as sementes que não passaram pelo choque enquanto que as sementes que passaram por pré-tratamento, a $13^{\circ} \mathrm{C}$ por $24 \mathrm{~h}$, aumentaram a incidência de sementes mortas, principalmente no potencial de -1,2MPa (Figura 1F).

Quando se avaliou a massa seca de parte aérea e raiz, os resultados obtidos com o choque de $7^{\circ} \mathrm{C}$ foram mais promissores que os obtidos com o choque de $13^{\circ} \mathrm{C}$ (Figura 2). Com a temperatura mais elevada não foi possível se detectar maior crescimento de plântulas pré-tratadas quando submetidas aos níveis de restrição hídrica, com exceção no potencial de $-0,9 \mathrm{MPa}$ (Figura 2B). O choque, no entanto, manteve aproximadamente constante a relação raiz/parte aérea. As sementes que não passaram pelo choque responderam com desenvolvimento desequilibrado da raiz em relação à parte aérea (Figura $2 \mathrm{H}$ ) o que não aconteceu com as sementes que passaram pelo choque. 
A
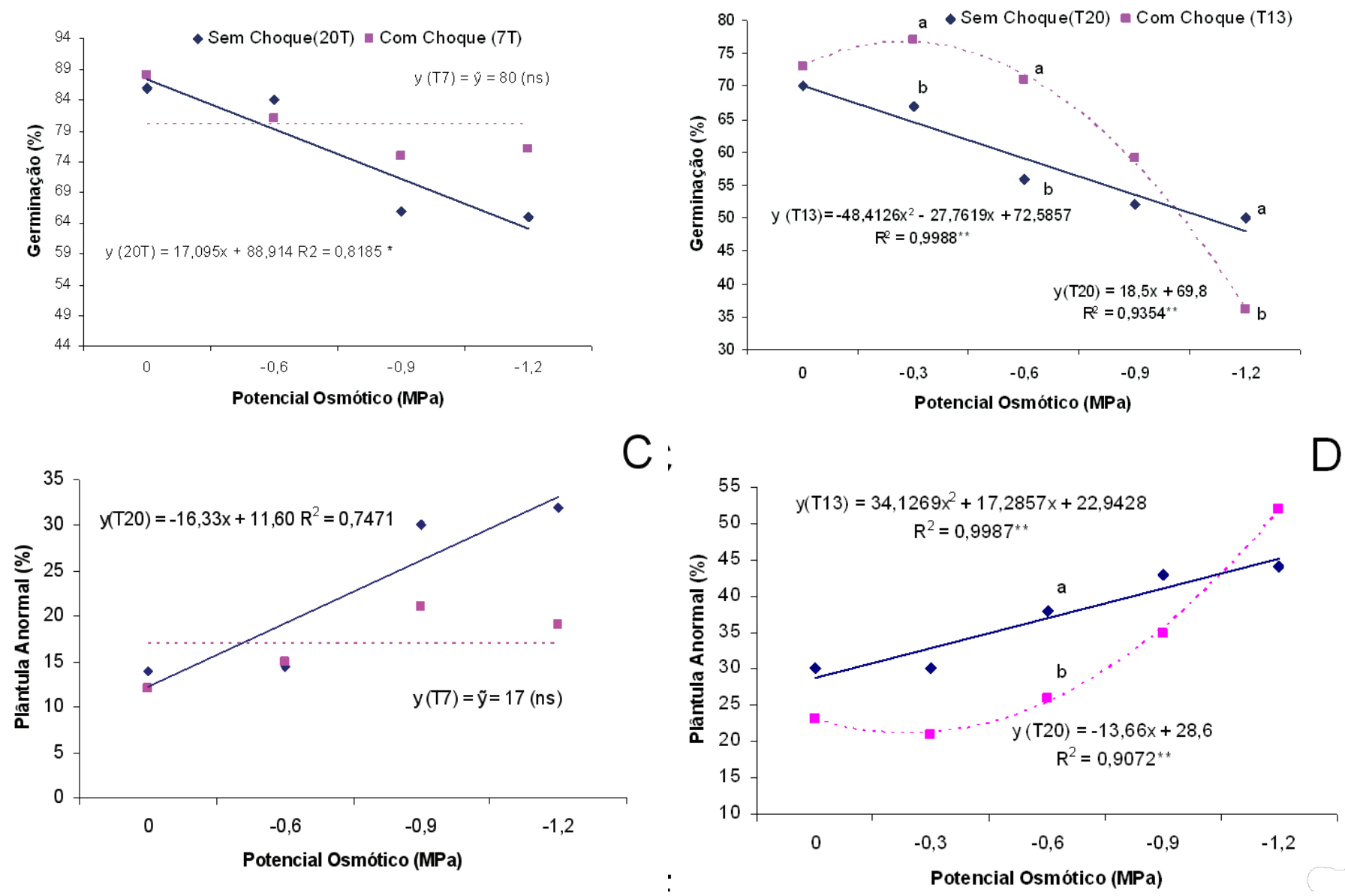

$E$

Potencial Osmótico (MPa)
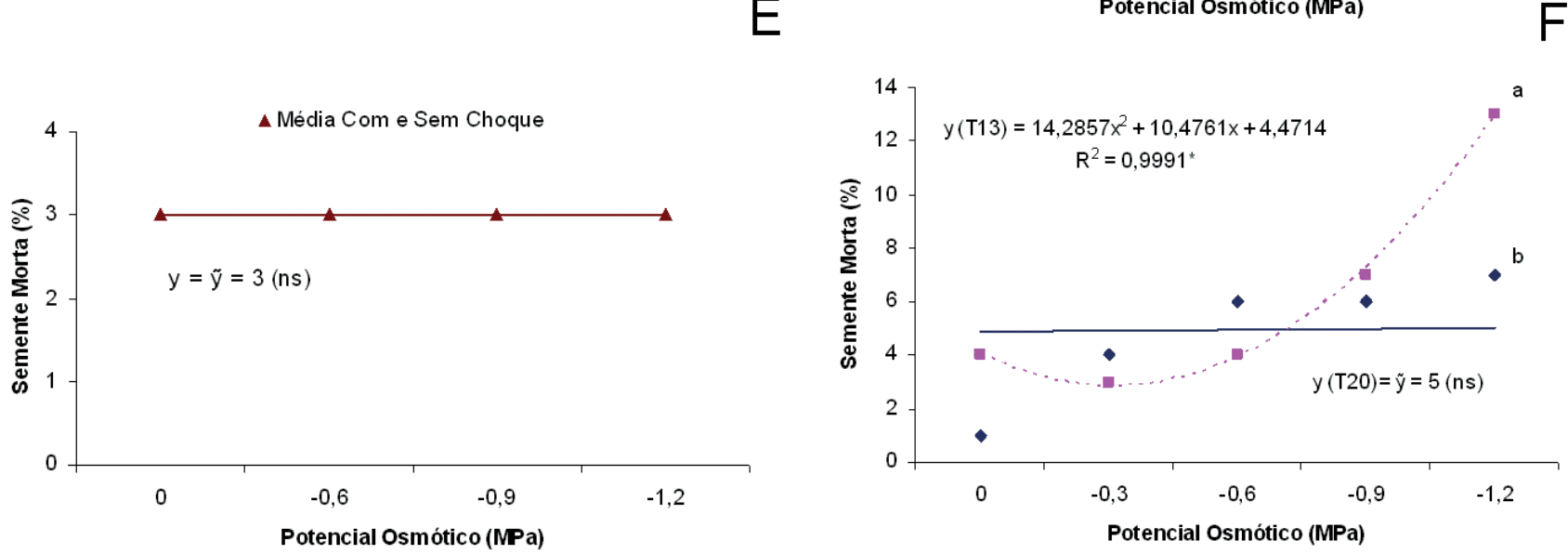

FIGURA 1. Germinação (A e B), plântulas anormais (C e D) e sementes mortas (E e F) de sementes de feijão pré tratadas e não pré tratadas com choque de $7^{\circ} \mathrm{C}$ (coluna a esquerda), e choque de ${ }^{130 C}$ (coluna a direita) submetidas aos níveis de potencial hídrico. Presidente Prudente, 2006. * Equações obtidas por regressão polinomial quando foi verificada significância do fator potencial osmótico na análise de variância pelo teste $F$. $R^{2}$ coeficiente de determinação da equação. Na vertical, de um mesmo potencial osmótico, pontos seguidos por letras distintas diferem significativamente pelo teste Tukey com $5 \%$ de significância. 

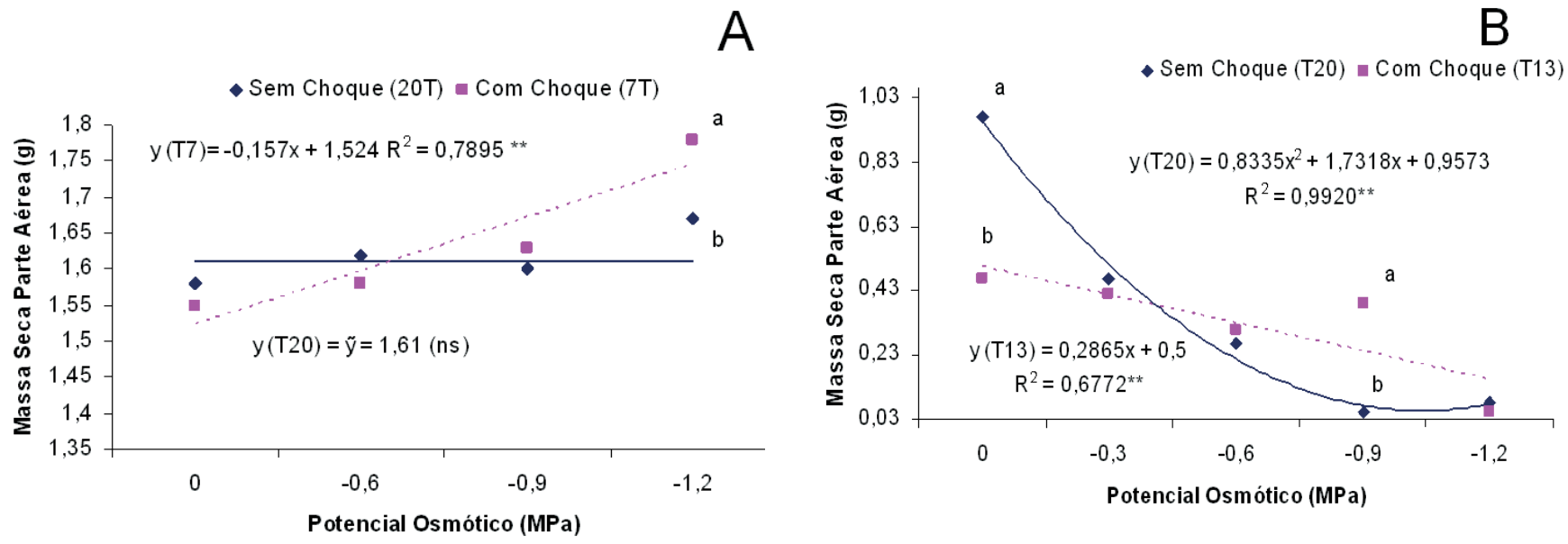

C

Potencial Osmótico (MPa)
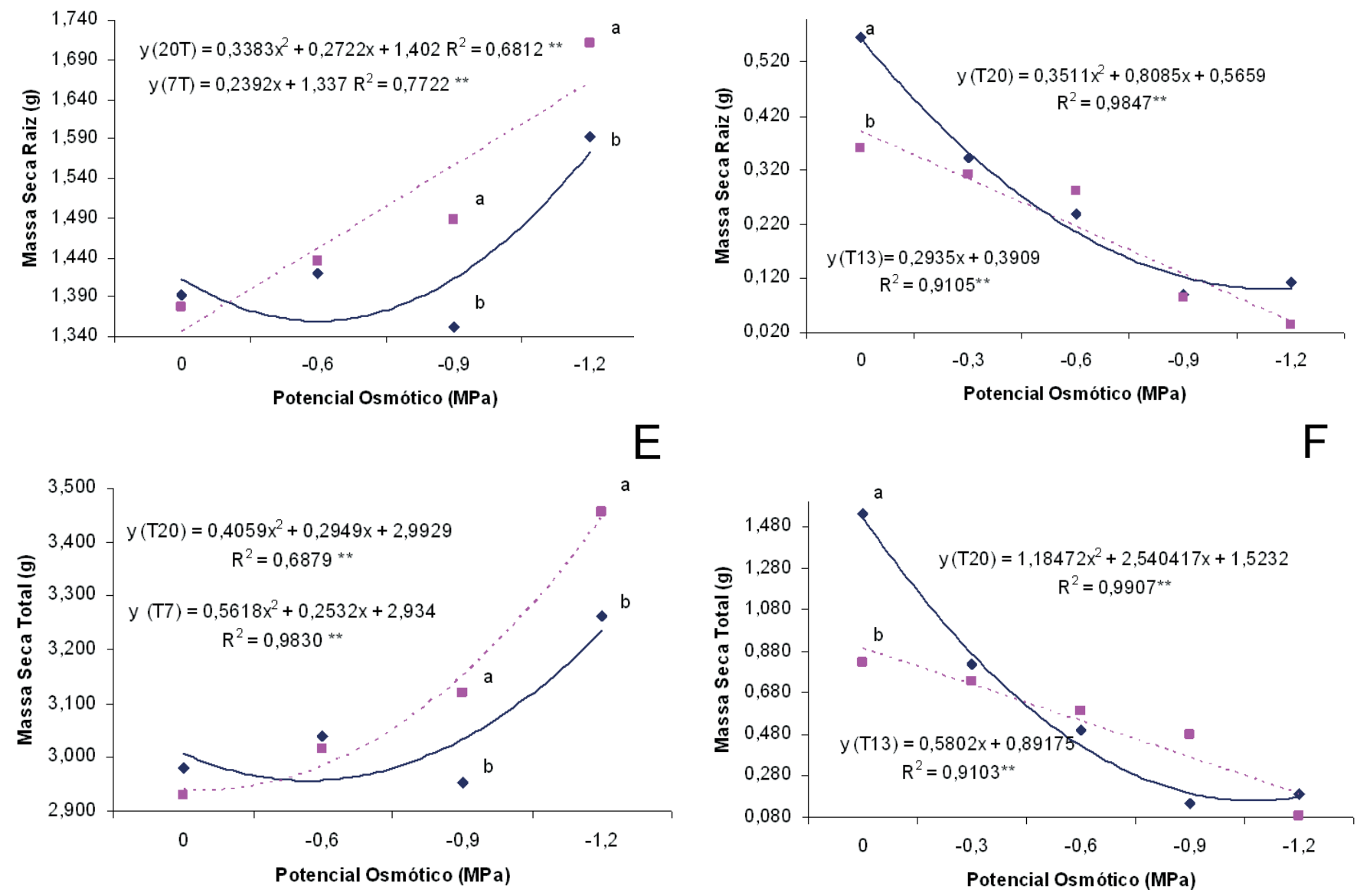

FIGURA 2. Massa seca de parte aérea (A e B), massa seca de raiz (C e D), massa seca total (E e F) e relação raiz/ parte aérea ( $\mathrm{G}$ e $\mathrm{H})$ de sementes de feijão pré tratadas e não pré tratadas com choque de $7^{\circ} \mathrm{C}$ (coluna a esquerda), e choque de $13^{\circ} \mathrm{C}$ (coluna a direita) e submetidas aos níveis de potencial hídrico. Presidente Prudente, 2006. R/PA relação raiz/parte aérea. * Equações obtidas por regressão polinomial quando foi verificada significância do fator potencial osmótico na análise de variância pelo teste $F$. $R^{2}$ coeficiente de determinação da equação. Na vertical, de um mesmo potencial osmótico, pontos seguidos por letras distintas diferem significativamente pelo teste Tukey com 5\% de significância. 
Os resultados observados para a massa seca de parte aérea, massa seca de raiz e massa seca total com o prétratamento de $7^{\circ} \mathrm{C}$ (Figura 2A, C e E) foram indicativos de tolerância cruzada pois mostraram que as sementes estressadas pelo choque melhoraram o nível de resposta ao estresse subseqüente, que, neste trabalho, foi representado pela deficiência de água. Os resultados foram mais expressivos nos maiores níveis de deficiência - 0,9 e -1,2MPa.

O choque quente, de $38^{\circ} \mathrm{C}$ por $24 \mathrm{~h}$, reduziu a germinação (Figura 3A) em todos os níveis de potencial hídrico. A produção de plântulas anormais (Figura $3 \mathrm{C}$ ), nas sementes que não passaram pelo choque, foi aumentada em função da deficiência hídrica enquanto que o das sementes que passaram pelo choque mantiveram-se constante. $\mathrm{O}$ número de sementes mortas não foi influenciado pelo choque quente nem pelos potenciais de água (Figura 3E). Os parâmetros que avaliaram o desenvolvimento de plântulas como massa seca de parte aérea (Figura 4A), massa seca de raiz (Figura 4C), massa seca total (Figura 4E) e relação parte aérea/raiz (Figura 4G) mostraram que o choque quente foi prejudicial ao desenvolvimento em todos os potenciais hídricos avaliados, indicando que a temperatura de $38^{\circ} \mathrm{C}$, mesmo que por $24 \mathrm{~h}$, foi suficiente para acentuar a deterioração que acabou por comprometer o desenvolvimento das plântulas. Nesse sentido, mesmo que tenham sido induzidas reações metabólicas das rotas de tolerância, os danos causados pela deterioração foram superiores, levando a um desempenho inferior das sementes submetidas ao choque quente. Sob altas temperaturas ocorrem alterações nas membranas celulares e enzimas. As membranas tornam-se mais permeáveis aos íons e ocorre aumento da solubilização e peroxidação dos lipídeos da membrana (Bewley e Black, 1994; Marcos Filho, 2005).

No ensaio 2, foi avaliada a redução da temperatura de choque quente de 38 para $33^{\circ} \mathrm{C}$. Com pré-tratamento de $33^{\circ} \mathrm{C}$ por $24 \mathrm{~h}$, ocorreu aumento da germinação em todos os potenciais estudados (Figura 3B), com conseqüente diminuição do número de plântulas anormais (Figura 3D) e sementes mortas (Figura 3F). Em sementes não tratadas, o desenvolvimento de plântulas foi maior quando não houve restrição hídrica, potencial zero (Figura 4B e F). Com restrição hídrica, o desenvolvimento das plântulas, analisado pela massa seca de parte aérea (Figura 4B), de raiz (Figura 4D) e total (Figura 4F), foi maior das sementes submetidas ao pré-tratamento de choque térmico de $33^{\circ} \mathrm{C}$. Nestas últimas, a relação raiz/parte aérea manteve-se constante com o aumento da restrição hídrica, enquanto as sementes não tratadas responderam com aumento da relação raiz/parte aérea (Figura $4 \mathrm{H}$ ). A temperatura de $33^{\circ} \mathrm{C}$ foi mais adequada ao pré-tratamento e permitiu a expressão de resposta de tolerância cruzada onde as sementes pré-tratadas desenvolveram plântulas mais tolerantes ao estresse hídrico.

A tolerância cruzada tem sido demonstrada em diferentes espécies no estágio de plântula ou posteriores, mas existem dúvidas sobre a possibilidade de indução em sementes germinando ou em plântulas muito jovens (Song et al., 2005). Em sementes secas parece não ser possível induzir proteínas resistentes ao calor como foi demonstrado por Jose et al. (2005) em um estudo no qual as sementes eram submetidas a altas temperaturas de secagem. Em outro estudo, plântulas de tomate não responderam com tolerância cruzada até atingirem 5 folhas, porém neste estágio ocorreu indução ao estresse com o pré-tratamento que foram mantidos pelo ciclo de vida da planta (Cayuela et al., 2001). Os resultados obtidos neste trabalho permitem afirmar que foi possível induzir tolerância cruzada no início do processo de germinação, após $24 \mathrm{~h}$ de embebição em sementes de feijão.

Para conter os efeitos do estresse, plantas iniciam um processo de aclimatação. Este processo pode requerer mudanças no fluxo de metabólitos através de diferentes rotas metabólicas, a supressão de rotas que podem envolver a produção de espécies reativas de oxigênio, a indução de vários genes de defesa tal como das proteínas de choque quente (HSPs) e a de enzimas seqüestradoras de radicais livres (Vierling, 1991). O complexo de sinalização, associados com a sensibilidade ao estresse, ativação de defesas e rotas de aclimatação, envolve espécies reativas de oxigênio, cálcio, proteínas reguladas por cálcio, redes de proteínas kinases e inter-relação entre diferentes fatores de transcrição (Bowler e Fluhr, 2000).

A tolerância cruzada pode ser explicada pelo alto grau de sobreposição entre conjuntos de genes determinantes da tolerância a um estresse particular (Rizhsky et al., 2002; Foolad et al., 2003) ou aos mecanismos de sinalização e resposta envolverem rotas metabólicas comuns como a respiração ou fotossíntese (Borisova et al., 2001).

$\mathrm{Na}$ literatura são escassos os exemplos de tolerância cruzada obtidos em sementes germinando. No entanto, Marin et al. (2004) relataram o efeito do alumínio associado ao estresse hídrico na germinação de sementes de guandu evidenciado até $-0,9 \mathrm{MPa}$, onde as menores concentrações de alumínio ( 0 a $5 \mathrm{mmol} . \mathrm{dm}^{-3}$ ) estimularam o desenvolvimento das plântulas em condições de estresse hídrico até -0,6MPa. Em trigo, sementes pré-tratadas a $33^{\circ} \mathrm{C}$ ou em solução $-0,8 \mathrm{MPa}$ de $\mathrm{NACl}$ por diversos períodos aumentaram tolerância ao subseqüente estresse hídrico ou de calor, mensurado por porcentagem de germinação e massa seca de 
plântulas, 5 dias após o início do experimento (Song et al., 2005). Os resultados obtidos neste trabalho mostraram que a aplicação de choque frio, após $24 \mathrm{~h}$ de embebição, por $24 \mathrm{~h}$ a 7

A

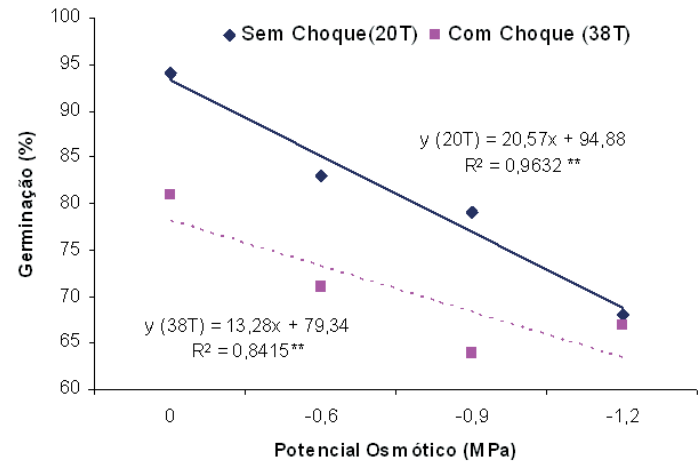

C

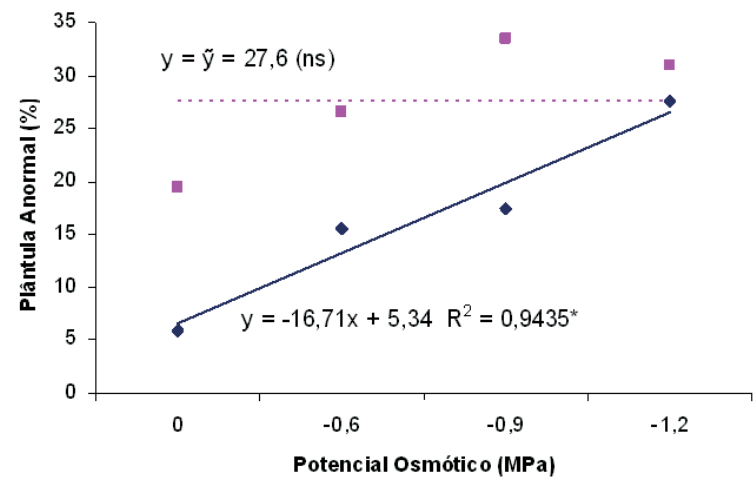

$E$

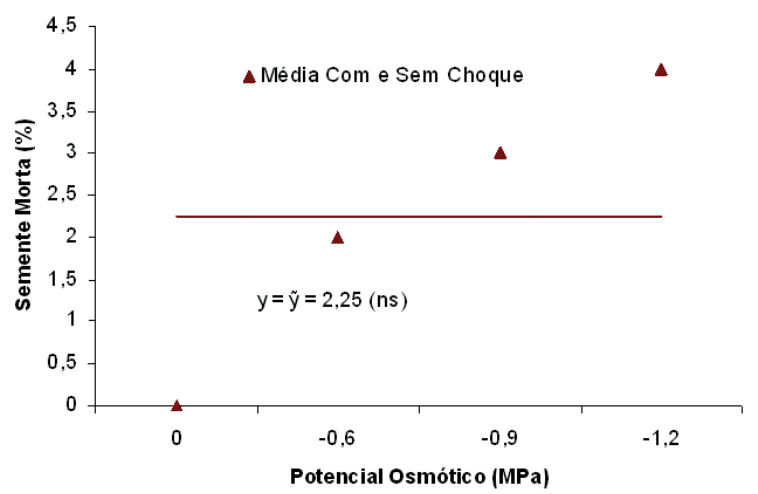

ou $33^{\circ} \mathrm{C}$, permitiu às plântulas suportarem o estresse hídrico subseqüente simulado por soluções de manitol.
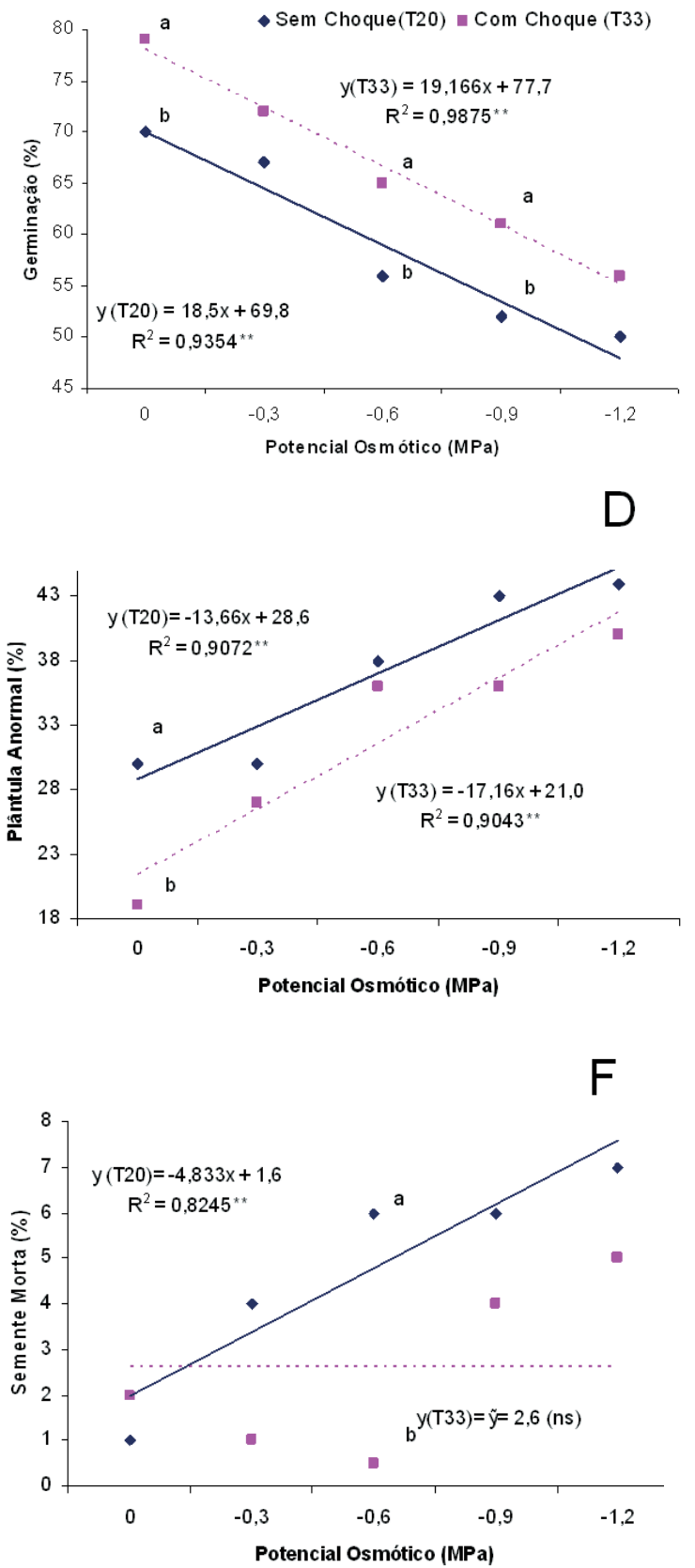

FIGURA 3. Germinação (A e B), plântulas anormais (C e D) e sementes mortas (E e F) de sementes de feijão pré tratadas e não pré tratadas com choque de $380 \mathrm{C}$ (coluna a esquerda), e choque de 33oC (coluna a direita) submetidas aos níveis de potencial hídrico. Presidente Prudente, 2006. * Equações obtidas por regressão polinomial quando foi verificada significância do fator potencial osmótico na análise de variância pelo teste F. R2 coeficiente de determinação da equação. Na vertical, de um mesmo potencial osmótico, pontos seguidos por letras distintas diferem significativamente pelo teste Tukey com $5 \%$ de significância. 
A
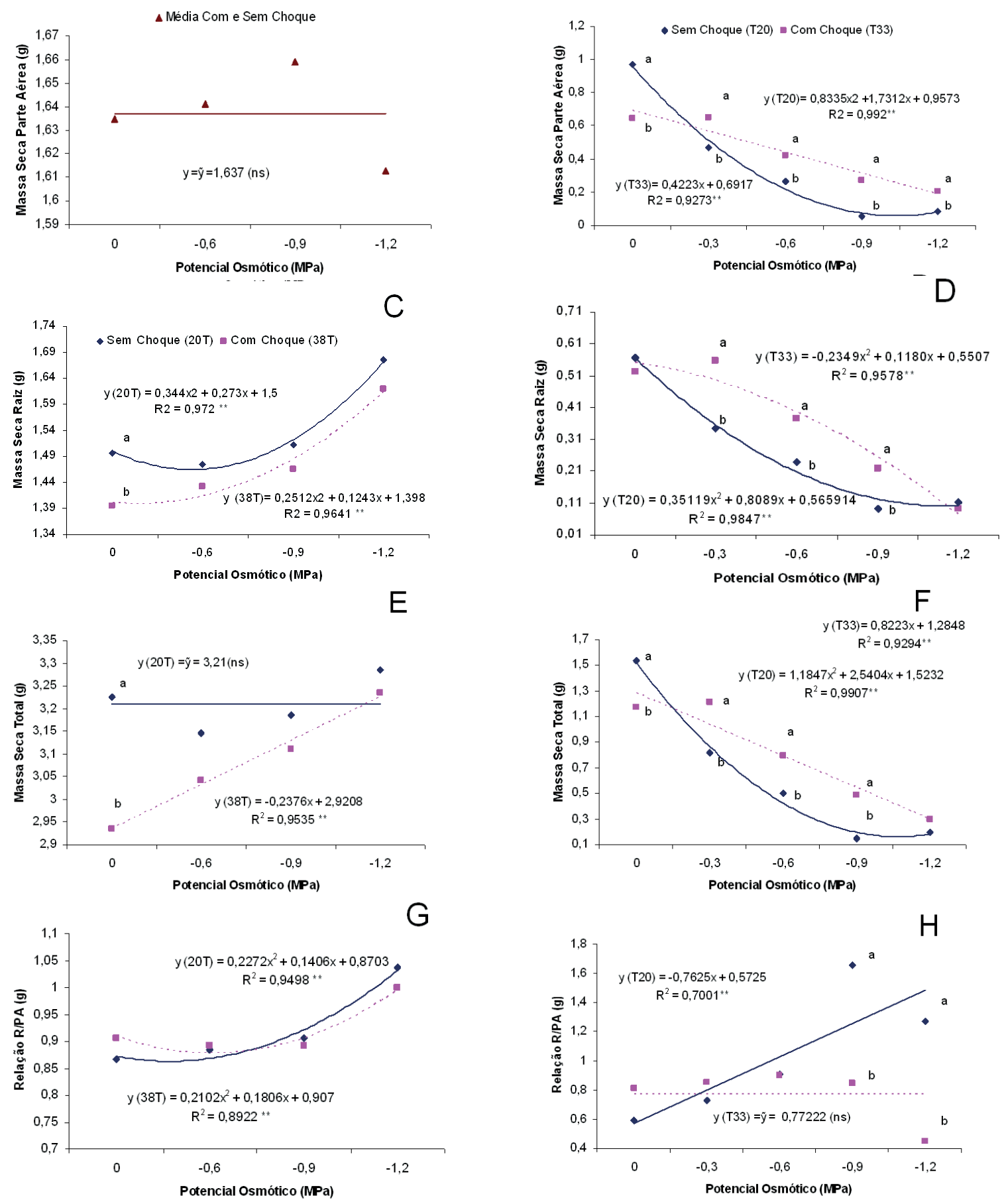

FIGURA 4. Massa seca de parte aérea (A e B), massa seca de raiz (C e D), massa seca total (E e F) e relação raiz/ parte aérea ( $\mathrm{G}$ e $\mathrm{H})$ de sementes de feijão pré tratadas e não pré tratadas com choque de $380 \mathrm{C}$ (coluna a esquerda), e choque de 33oC (coluna a direita) e submetidas aos níveis de potencial hídrico. Presidente Prudente, 2006. R/PA relação raiz/parte aérea. * Equações obtidas por regressão polinomial quando foi verificada significância do fator potencial osmótico na análise de variância pelo teste $F$. $R 2$ coeficiente de determinação da equação. Na vertical, de um mesmo potencial osmótico, pontos seguidos por letras distintas diferem significativamente pelo teste Tukey com 5\% de significância. 


\section{CONCLUSÕES}

O melhor desempenho das sementes que passaram por choque, de $7^{\circ} \mathrm{C}$ por $24 \mathrm{~h}$ ou de $33^{\circ} \mathrm{C}$ por $24 \mathrm{~h}$, à restrição hídrica no início do desenvolvimento permite afirmar que ocorreu indução de tolerância cruzada e que esta pode ser induzida no início do processo de embebição em sementes de feijão.

\section{REFERÊNCIAS}

ARAÚJO, S.J.L.; RUMJANEK, N.G.; PINHEIRO, M.M. Small heat shock proteins genes are differentially expressed in distinct varieties of common bean. Brazilian Journal of Plant Physiology, v. 15, n. 1, p. 33-41, 2003.

BEWLEY, J.D.; BLACK, M. Seeds: physiology of development and germination. 2.ed. New York: Plenum press, 1994. 445p.

BORISOVA, T.A.; BUGAJE, S.M.; MESHKOVA, N.V.; VLASOV, P.V. Heat shock increases the tolerance of Plants to UV-B radiation: 1. growth, development, and water supply to tissues. Russian Journal of Plant Physiology, v.48, n.4, p.507-513, 2001.

BOWLER, C.; FLUHR, R. The role of calcium and activated oxygens as signals for controlling cross-tolerance. Trends Plant Science, v.5, p.241-246, 2000.

BRAAK, J.P. ; KOISTRA, E. A susccesful cross between Phaseolus vulgaris L. and Phaseolus ritensis Jones, with the aid of embryor culture. Euphytica, v. 24, p. 669-679, 1995.

BRACCINI, A.L.; RUIZ, H.A.; BRACCINI, M.C.L.; REIS, M.S. Germinação e vigor de sementes de soja sob estresse hídrico induzido por soluções de cloreto de sódio, manitol e polietilenoglicol. Revista Brasileira de Sementes, v.18, n.1, p.10-16, 1996.

BRAGA, L.F.; SOUSA, M.P.; BRAGA, J.F.; SÁ, M.E. Efeito da disponibilidade hídrica do substrato na qualidade fisiológica de sementes de feijão. Revista Brasileira de Sementes, v.21, n.2, p.95-102, 1999.

BRASIL, Ministério da Agricultura. Regras para análises de sementes. 1992. 365p

CAYUELA, E.; ESTAÑ, M.T.; PARRA, M.; CARO, M.; BOLARIN, M.C. $\mathrm{NaCl}$ pre-treatment at the seedling stage enhances fruit yield of tomato plants irrigated with salt water. Plant and Soil, v.230, p. 231-238, 2001.

COSTA, P.C.; CUSTÓDIO, C.C.; MACHADO NETO, N.B.; MARUBAYASHI, O.M. Estresse hídrico induzido por manitol em sementes de soja de diferentes tamanhos. Revista
Brasileira de Sementes, v.26, n. 2, p. 105-113, 2004.

DURVAL, D.N.; FANCELLI, A.L. Produção de feijão. Guaíba:Agropecuária, 385p., 2000.

FERGUSON, D. L., J.A.; PAULSEN, G. M. Ubiquitin pool modulation and protein degradation in wheat roots during high temperature stress. Plant Physiology, v. 92, p. 740- 746, 1990.

FONSECA, S.C.L.; PEREZ, S.C.J.G.A.; Ação do polietileno glicol na germinação de sementes de Adenanthera pavonina L. e o uso de poliaminas na atenuação do estresse. Revista Brasileira de Sementes, v.25, n.1, p. 1-6, 2003.

FOOLAD, M.R.; SUBBIAH, P.; KRAMER, C.; HARGRAVE, G.; LIN, G.Y. Genetic relationships among cold, salt and drought tolerance during seed germination in an interspecific cross of tomato. Euphytica, v.130, p.199206, 2003.

GIMALOV, F. P.; CHEMERIS, A. V. ; VAKHITOV, V. A. Synthesis of cold shock proteins in wheat tribe seedlins of the family Poaceae. Russian Journal of Plant Physiology, v.43, n.228-231, 1996.

HARDWICK, R. C. ; ANDREWS, D. J. Selection for cold tolerance in Phaseolus vulgaris yields of selected lines grown in warm and cold environments. Annals of Applied Biology, v. 95, p. $249-259,1980$.

JOSE, S.C.B.R.; VON PINHO, E.V.R.; VON PINHO, R.G.; SILVEIRA, C.M. Padrão eletroforético de proteínas resistentes ao calor em sementes de milho. Pesquisa Agropecuária Brasileira, v.40, n.2, p. 115-121, 2005.

KUMARI, G.J.; REDDY, A.M.; NAIK, S.T.; KUMAR, S.G.; PRASANTHI, J.; SRIRANGANAYAKULU, G.; REDDY, P.C.; SUDHAKAR, C. Jasmonic acid induced changes in protein pattern, antioxidative enzyme activities and peroxidase isozymes in peanut seedlings. Biologia Plantarum, v.50, n.2, p.219-226, 2006.

MACHADO NETO, N.B.; CUSTÓDIO, C.C.; COSTA, P.R.; DONÁ, F.L. Deficiência hídrica induzida por diferentes agentes osmóticos na germinação e vigor de sementes de feijão. Revista Brasileira de Sementes, v.28, n.1, p.142-148, $2006 \mathrm{a}$.

MACHADO NETO, N.B.; CUSTÓDIO, C.C.; GATTI, A.B.; PRIOLI, M.R.; CARDOSO, V.J.M. Proline: use as an indicator of temperature stress in bean seeds. Crop Breeding and Applied Biotechnology, v.4, p. 330-337, 2004.

MACHADO NETO, N.B.; PRIOLI, M.R.; GATTI, A.B.; CARDOSO, V.J.M. Temperature effects on seed germination in races of common beans (Phaseolus vulgaris L.). Acta 
Scientiarum Agronomy, v. 28, n. 2, p.155-164, 2006 b.

MAITY, S.; BANERJEE, G.; ROY, M.; PAL, C.; PAL, B.; CHAKRABARTI, D.; BHATTACHARJEE, A. Chemical induced prolongation of seed viability and stress tolerance capacity of mung bean seedlings. Seed Science and Technology, v.28, p.155-162, 2000.

MARCOS FILHO, J. Fisiologia de sementes de plantas cultivadas. Piracicaba: FEALQ, 2005. 495p. (Biblioteca de Ciências Agrárias Luiz de Queiroz, v.12).

MARIN, A.; SANTOS, D.M.M.; BANZATTO, D.A.; FERRAUDO, A.S. Germinação de sementes de guandu sob efeito da disponibilidade hídrica e de doses subletais de alumínio. Bragantia, v. 63, n. 1, p. 13-24, 2004.

MARUR, C.J.; SODEK, L.; MAGALHÃES, A.C. Free aminoacids in leaves of cotton plants under water deficit. Revista Brasileira de Fisiologia Vegetal, v.6, p.103-108, 1994.

MATOVINA, V.B.; BLAKE, T.J. Seed treatment with the antioxidant Ambiol enhances membrane protection in seedlings exposed to drought and low temperatures. Trees, v. 15, p.163-167, 2001.

McCUE, P.; ZHENG, Z.; PINKHAM, J.L.; SHETTY, K. A model for enhanced peã seedling vigour following low $\mathrm{pH}$ and salicylic acid treatments. Process Biochemistry, v.35, p.603-613, 2000.

NAKAGAWA, J. Testes de vigor baseados nos desempenhos das plântulas. In: KRZYZANOWSKI, F.C.; VIEIRA, R.D. ; FRANÇA NETO, J.B. (Ed.).

Vigor de sementes: conceitos e testes. Londrina:ABRATES, 1999. p.2-1-2-24.

NEID, S.L.; BIESBOER, D.D. Alleviation of salt-induced stress on seed emergence using soil additives in a greenhouse. Plant and Soil, v. 268, p.303-307, 2005.

NEPOMUCENO, A.L.; OOSTERHUIS, D.; STEWART, J.McD et al. Expression of heat shock protein and trehalose6-phosphate syntase homologues induced during water deficit in cotton. Brazilian Journal of Plant Physiology, v.14, n.1, p.11-20, 2002.

PANDA, S.K.; KHAN, M.H. Changes in growth and superoxide dismutase activity in Hydrilla verticillata L. under abiotic stress. Brazilian Journal of Plant Physiology, Pelotas, v. 16, n. 2, p. 115-118, 2004.

PASTORI, G.M.; FOYER, C.H. Common components, networks, and pathways of cross-tolerance to stress. The central role of "redox" and abscisic acid-mediated controls. Plant Physiology, v.129, p.460-468, 2002.
RAB, A. ; SALTVEIT, M. E. Sensitivity of seedling radicles to chilling and heat-shock-induced chilling tolerance. Journal of American Society for. Horticultural Science, v.121, n.4, p. $711-715,1996$.

RIZHSKY, L.; LIANG, H.; MITTLER, R. The combined effect of drought stress and heat shock on gene expression in tobacco. Plant Physiology, v.130, p. 1143-1151, 2002.

SABEHAT, A., WEISS, D.; LURIE, S. The correlation between heat-shock protein accumulation and persistence and chulling tolerance in tomato fruit. Plant Physiology, v.110, p.531-537, 1996.

SANTOS, V.L.M.; SILVA, R.F.; SEDIYAMA,T.; CARDOSO, A.A. Utilização do estresse salino na qualidade das sementes de genótipos de soja (Glycine max (L.) Merrill). Revista Brasileira de Sementes, v.18, n.1, p.83-87, 1996.

SHIM, I.S; MOMOSE, Y.; YAMAMOTO, A.; KIM, D.W.; USUI, K. Inhibition of catalase activity by oxidative stress and its relationship to salicylic acid accumulation in plants. Plant Growth Regulation, v. 39, p.285-292, 2003.

SILVA, V.R.; REICHERT, J.M.; REINERT, D.J. Variação na temperatura do solo em três sistemas de manejo na cultura do feijão. Revista Brasileira de Ciência do Solo, v. 30, n. 3, p.391-399, 2006.

SONG, S.Q.; LEI, Y.B.; TIAN, X.R. Proline metabolism and cross-tolerance to salinity and heat stress in germinating wheat seeds. Russian Journal of Plant Physiology, v. 52, n.6, p. 897-904, 2005.

SOUZA, G.M.; CARDOSO, V.J.M. Effects of different environmental stress on seed germination. Seed Science Technology, v.28, n.3, p.621-630, 2000.

SUNG SHIM, I; MOMOSE, Y.; YAMAMOTO, A.; KIM, D.; USUI, K. Inhibition of catalase activity by oxidative stress and its relationship to salicylic acid accumulation in plants. Plant Growth Regulation, v. 39, p.285-292, 2003.

TAIZ, L.; ZEIGER, E. Fisiologia vegetal. 3ed. Porto Alegre: Artmed, 2004.

TAKAHASHI, R.; JOSHEER, N.; KITAGAWA, Y. Induction of chilling resistance by water stress, and cDNA sequence Analysis and expression of water stress-regulated genes in rice. Plant Molecular Biology, v.26, p.339-352, 1994.

VIERLING, E. The roles of heat shock proteins in plants. Annual Review of Plant Physiology and Plant Molecular Biology, v. 42, p.579-620, 1991.

WAHID, A.; SHABBIR, A. Induction of heat stress tolerance in barley seedlings by pré-sowing seed treatment 
with glycinebetaine. Plant Growth Regulation, v.46, p.133141, 2005.

ZAITER H., BAYDOOUN, E. ; SAYYED-HALLAK, M. Genotypic variation in the germination of common bean in response to cold temperature stresse. Plant and Soil, v.163, p. 95-101, 1994.

ZONTA, E.P.; MACHADO, A.D.; SILVEIRA JUNIOR., P. Sistemas de análise estatística para microcomputadores SANEST. Pelotas: UFPel, 1984. (Registro SEI no06606-0, Categoria AO). 